\title{
Interresponse time analysis of behavioral interaction
}

\author{
R. G. WEISMAN \\ Queen's University at Kingston, Kingston, Ontario, Canada K7L SN6 \\ and \\ E. R. DAVIS \\ Emory University, Atlanta, Georgia 30322
}

\begin{abstract}
Five pigeons keypecked for food on a two-component multiple schedule. One stimulus was associated with a variable-interval 2 -min unchanged component. A second stimulus was associated with an equal variable-interval schedule, then changed to differential reinforcement of low rate. During discrimination training, the overall rate of responding in the first, unchanged, component declined, but later was slightly higher than during prior nondifferential training. A more detailed analysis of responding during the unchanged component showed that responses with both short and quite long interresponse times increased in probability by the final sessions of discrimination training.
\end{abstract}

The rate of responding in one component, associated with a discriminative stimulus $\left(\mathrm{S}_{1}\right)$, of a multiple schedule can be affected when the schedule of reinforcement in another component, associated with a second stimulus $\left(S_{2}\right)$, is changed. These behavioral interactions (Reynolds \& Catania, 1961) are of two general kinds: The rate of response in the presence of $S_{1}$ can change in the same or in the opposite direction as the change in responding in the presence of $S_{2}$. In current usage the latter interaction is termed contrast and the former induction.

Although changes in rates of responding in multiple schedules have been the subject of considerable research, corresponding changes in the distributions of interresponse time (IRT) have not. The IRT distributions of responses to $S_{1}$ have been reported only by Reynolds and Catania and by Spealman and Gollub (1974) for multiple schedules alternating, respectively, differential reinforcement (VI) with extinction. In both studies, the frequency of responses with IRTs shorter than $2 \mathrm{sec}$ increased with the overall rate of responding to $S_{1}$. Distributions of IRTs might make sources of behavioral interaction explicit when schedules with easily discernible effects on the IRT distribution are used as components in a multiple schedule. Accordingly, the present experiment examined the IRT distributions of responding to discriminative

The authors wish to thank R. A. Boakes for his helpful comments on an earlier version of this paper. This research was supported by research grants from the National Research Council of Canada and the Ontario Mental Health Foundation. The paper was prepared while R. G. Weisman was a Canada Council Leave Fellow at Sussex University in England. Reprints may be obtained from R. G. Weisman, Department of Psychology, Queen's University, Kingston, Ontario, Canada. stimuli associated, respectively, with VI and DRL in multiple-schedule discrimination training.

\section{METHOD}

\section{Subjects}

Five experimentally naive male Silver King pigeons, 6-8 years old, were maintained at about $75 \%$ of free-feeding weight throughout the experiment.

\section{Apparatus}

A Lehigh-Valley Model 1519 pigeon chamber was used. An Industrial Electronics Engineers in-line display cell transilluminated the key. Vertical and horizontal white lines, $3 \mathrm{~mm}$ wide by $22 \mathrm{~mm}$ long, on a green surround were presented by the display cell. The reinforcer was 3-sec access to mixed grain, illuminated during food presentation by a white lamp above the hopper. No houselight was used. White noise served to mask most extraneous sounds. Scheduling and recording equipment, including a PDP-8/I computer, were located in a separate room.

\section{Procedure}

Keypeck training was followed by sessions in which the requirement for reinforcement was gradually increased to 25 responses. The stimuli on the key during this preliminary training were those presented during all later sessions. Throughout the experiment, a horizontal line $\left(S_{1}\right)$ and a vertical line $\left(S_{2}\right)$ presented on a green surround appeared behind the key during alternate 4-min trials. The key was darkened during a 10-sec timeout between trials. Each session terminated after 16 trials. An IRT analysis was conducted for Trials 3-16.

During the nondifferential reinforcement phase of the experiment, $S_{1}$ and $S_{2}$ were correlated with identical but independent variable-interval (VI) component schedules. After four sessions with mult VI $1 \mathrm{~min}$ VI $1 \mathrm{~min}$, the birds had 18 sessions with mult VI 2 min VI 2 min.

Discrimination training sessions were identical to prior nondifferential reinforcement sessions, except that the schedule of reinforcement associated with $S_{2}$ was shifted from VI to DRL. In a DRL $t$-sec schedule, responses with IRTs longer than $t$ sec are reinforced and responses with IRTs shorter than $t$ sec postpone the reinforcer for $t$ sec. After three sessions with mult VI 2 min DRL $6 \mathrm{sec}$, the birds had 12 sessions with mult VI 2 min DRL $12 \mathrm{sec}$. 


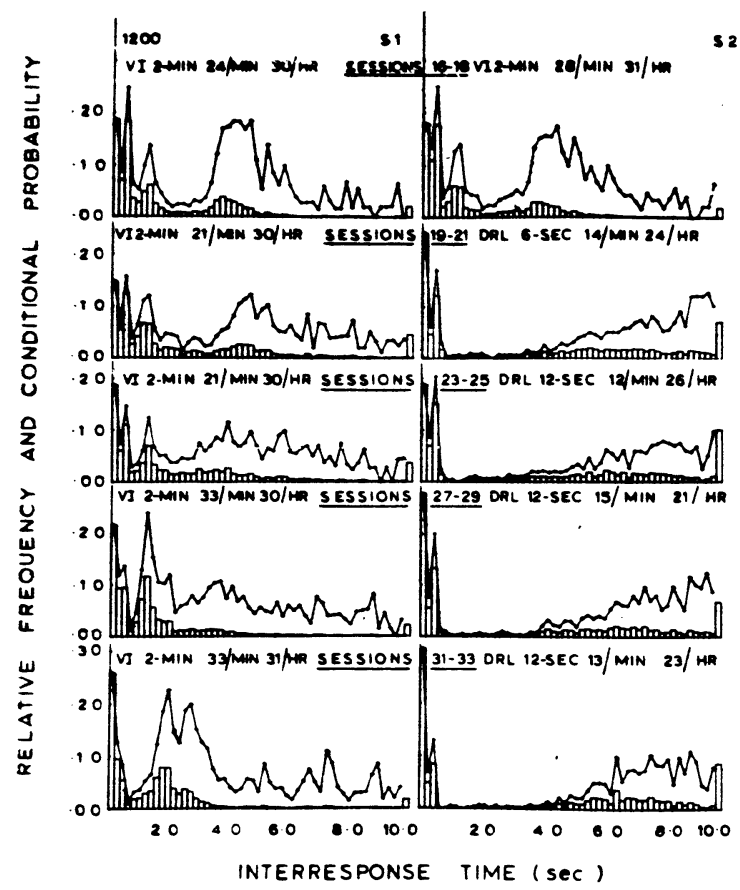

Figure 1. Relative frequency and conditional probability distributions of responding in .2-sec IRT categories to $S_{1}$ and $S_{2}$ for Bird 1200. Also given are responses/min and reinforcements $/ h$ for three session blocks.

\section{RESULTS}

Figure 1 shows the relative frequency and conditional probability of responses in each .2-sec interresponse time category, and the overall rates of responses $/ \mathrm{min}$ and of reinforcements $/ \mathrm{h}$ for the last three sessions of nondifferential training and three session blocks of discrimination training for Bird 1200. Interresponse times/opportunities, or IRTs/OP (Anger, 1956), estimate the conditional probability of a response in any given IRT category independently of the relative frequency of responses with shorter IRTs. Specifically, the IRTs/OP measure divides the number of responses in an IRT category by the number of responses in that and all remaining categories. However, when few or no responses occur in. the remaining IRT categories, the conditional probability statistic becomes highly variable and unreliable (Blough, 1969). In the present work, the conditional probability of responding in any given IRT category was calculated and plotted only if the remaining opportunities to respond included at least $1 \%$ of the total number of responses in the distribution.

The shift to DRL in $S_{2}$ (see Figure 1) engendered a reduced rate of responding to $S_{2}$. Also, in the $S_{2}$ component the relative frequency and conditioned probability of responses with long IRTs increased with further mult VI DRL sessions, but the relative frequency of responses with IRTs shorter than $.6 \mathrm{sec}$ was not reduced. The overall rate of responding to $S_{1}$, shown in Figure 1, at first declined during discrimination training, but by Sessions 27-29 was slightly higher than during nondifferential training. Also, in the $S_{1}$ component, the conditional probability of long IRTs increased noticeably during discrimination training. By Sessions 27-29, the conditional probability of responses with IRTs shorter than $3.0 \mathrm{sec}$ had also increased. Performance across discrimination training seen in Bird 1200 was fairly typical of the other four birds as well.

Figure 2 shows conditional probability distributions in 1.0-sec IRT categories, and overall rates of responding and reinforcement to $S_{1}$ in the last three sessions of nondifferential training (Sessions 16-18) and to $S_{1}$ and $S_{2}$ in the last three sessions of discrimination training (Sessions 31-33) for Birds $2035,2213,6920$, and 2633. Overall rates of responding to $S_{1}$ increased slightly, 2-14 responses/ min, from nondifferential to discrimination training. Also, in the $S_{1}$ component, the modal IRT was shorter, but responses with long IRTs were more probable during discrimination training (the middle panels) than before (the upper panels). During $\mathrm{S}_{2}$ the overall response rate was 18-26 responses lower than in $S_{1}$. The conditional probability of responding in the $\mathbf{S}_{2}$ component (the lower panels) was high at $1 \mathrm{sec}$, low at $2-3 \mathrm{sec}$, then increased gradually at longer IRTs.

A summary of actual response frequencies of selected summary IRT classes for $S_{1}$ during the last three sessions of nondifferential reinforcement, and for $S_{1}$ and $S_{2}$ during the last three sessions of

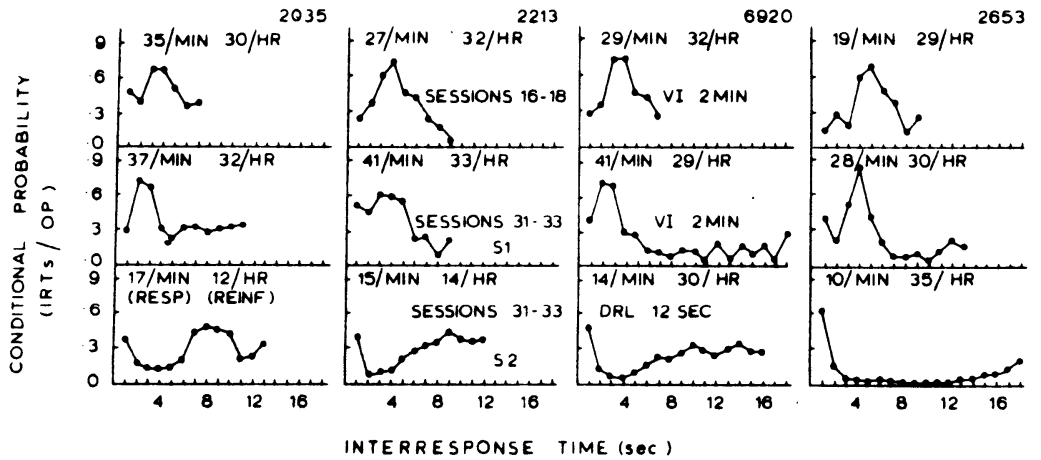

Figure 2. Conditional probability distributions for responding in 1.0-sec IRT categories. Also given are responses/min and reinforcements/h. The last three sessions of nondifferential reinforcement for $S_{1}$ and discrimination training for $S_{1}$ and $S_{2}$. 
discrimination training, is shown in Table 1. The first class, containing only responses with short IRTs (less than $.6 \mathrm{sec)}$ was not consistently affected by mult VI DRL training. A substantial number of these bursts of responses were emitted in $S_{1}$ and $S_{2}$. The number of responses with short- to intermediatelength IRTs $(.6$ to $3.0 \mathrm{sec})$ increased in $S_{1}$ but decreased in $S_{2}$ markedly. The number of responses with intermediate-length IRTs $(3.0$ to $6.0 \mathrm{sec})$ declined in both $S_{1}$ and $S_{2}$. Responses with much longer IRTs (over $6.0 \mathrm{sec}$ ) increased, of course, in $S_{2}$ associated with DRL, but also tended to increase in $S_{1}$ as well. Moreover, the number of responses with long IRTs in $S_{1}$ was correlated with the number of responses with long IRTs in $S_{2}$. These results are in good agreement with those based on relative frequencies and conditional probability analyses in Figures 1 and 2, respectively.

\section{DISCUSSION}

The IRT distributions and rates of responding emitted during the VI and DRL components of the multiple schedule examined in the present work have much in common with those obtained with individual VI and DRL schedules of reinforcement in published research. Multimodal and somewhat idiosyncratic IRT distributions of VI responding similar to those seen by Blough and Blough (1968) and Spealman and Gollub (1974) were obtained in the present work. Responding in bursts did not change systematically under DRL or VI in the present work, but under DRL fewer intermediate-length IRTs and many more long IRTs were seen, as in work reported by Kramer and Rilling (1969) and Reynolds (1964). Also, IRT distributions of conditional probability of responding under DRL shown by these authors have the same form as ours, shown in Figure 2.

In common with Spealman and Gollub (1974), who studied mult VI EXT discrimination training, we obtained an increase in the probability of responses with short- to intermediate-length IRTs in the VI component of the multiple schedule, in our case, mult VI DRL discrimination training. In the present study, every bird showed a shift toward a shorter modal IRT, but the resulting change in the overall rate of response was small (from $6 \%$ to $52 \%$ ) compared to the change in overall response rate (approximately $35 \%$ to $130 \%$ ) generated by mult VI 3 min EXT in the Spealman and Gollub study.

Opposing overall behavioral contrast were other, and heretofore unobserved, changes in responding to $S_{1}$. The probabilities of responses with intermediate length decreased, while those of responses with long IRTs increased systematically during $S_{1}$ following the shift to mult VI DRL. During early discrimination training sessions, the overall rate responding recovered and even increased, but responses with long IRTs remained generally more probable than prior to discrimination training. Since the most likely source of change in the frequency of intermediate and long IRTs seen in $S_{1}$ would appear to be similar IRTs seen in $S_{2}$, it seems reasonable to term these changes instances of IRT induction. Indeed the opposite tendency for responses with shortto intermediate-length IRTs to increase might be termed IRT contrast.

Mackintosh (1974) and Boakes, Halliday, and Mole (in press) recommend caution in describing slight changes in responding as behavioral interactions without a return to nondifferential reinforcement or the inclusion of a control group. Thus, slight, but reliable from bird to bird, increases in the probability of responses with short IRTs and in overall response rate in the present work might only reflect the tendency for the rate of responding to increase over even extended VI training. Of course,
Table 1

Responses Per Hour in Summary IRT Classes in $S_{1}$ During Nondifferential Reinforcement and $S_{1}$ and $S_{2}$ During Discrimination Training

\begin{tabular}{rcrrrr}
\hline & & \multicolumn{4}{c}{ IRT Classes (sec) } \\
\cline { 3 - 6 } Bird & Stimulus & .6 & 3.0 & 6.0 & $>6.0$ \\
\hline \multirow{6}{*}{1200} & $S_{1}$ & 636 & 378 & 357 & 68 \\
& $S_{1}$ & 805 & 914 & 163 & 90 \\
& $S_{2}$ & 314 & 15 & 71 & 319 \\
& $S_{1}$ & 880 & 988 & 246 & 67 \\
& $S_{1}$ & 488 & 1581 & 87 & 85 \\
& $S_{2}$ & 263 & 251 & 170 & 275 \\
& $S_{1} 213$ & 259 & 990 & 264 & 42 \\
& $S_{1}$ & 816 & 1410 & 183 & 62 \\
& $S_{2}$ & 248 & 125 & 230 & 234 \\
& $S_{1}$ & 299 & 1264 & 206 & 32 \\
& $S_{1}$ & 505 & 1758 & 53 & 64 \\
& $S_{2}$ & 301 & 118 & 86 & 275 \\
& $S_{1}$ & 153 & 402 & 446 & 73 \\
& $S_{1}$ & 365 & 1118 & 220 & 34 \\
& $S_{2}$ & 285 & 104 & 104 & 167 \\
\hline
\end{tabular}

decreased response rates at the beginning of discrimination training and a continuing increased probability of long IRTs can hardly be attributed to gradual increases in response rate.

The present results, although only preliminary, appear to encourage the further study of IRT distributions of responding in multiple schedules. It is not clear that opposing changes in the IRT distribution during $S_{1}$ do not often cancel each other out, leaving the overall rate of responding only slightly changed. Moreover, IRT analyses might prove a useful adjunct to rate analysis even when the change in the overall rate of responding is large.

\section{REFERENCES}

ANGER, D. The dependence of interresponse times upon the relative reinforcement of different interresponse times. Journal of Experimental Psychology, 1956, 52, 145-161.

Blough, D. S. Generalization gradient shape and summation in steady-state tests. Journal of the Experimental Analysis of Behavior, 1969, 12, 91-104.

Blough, P. M., \& Blough, D. S. The distribution of interresponse times in the pigeon during variable-interval reinforcement. Journal of the Experimental Analysis of Behavior, 1968, 11, 23-27.

Boakes, R. A., Halliday, M. S., \& Mole, J. S. Successive discrimination training with equated reinforcement frequencies: Failure to obtain behavior contrast. Journal of the Experimental Analysis of Behavior, in press.

KRAMER, T. J., \& Riling, M. Effects of timeout on spaced responding in pigeons. Journal of the Experimental Analysis of Behavior, 1969, 12, 283-288.

Mackintosh, N. J. The psychology of animal learning. Academic Press: London, 1974.

ReYNolds, G. S. Temporally spaced responding in pigeons: Development and the effects of deprivation and extinction. Journal of the Experimental Analysis of Behavior, 1964, 7, 415-421.

Reynolds, G. S., \& Catania, A. C. Behavioral contrast with fixed-interval and low-rate reinforcement. Journal of the Experimental Analysis of Behavior, 1961, 4, 387-391.

Spealman, R. D., \& Gollub, L. R. Behavioral interactions in multiple variable-interval schedules. Journal of the Experimental Analysis of Behavior, 1974, 22, 471-481.

(Received for publication March 21, 1976.) 